\title{
LexCult
}

ARTIGOS

DOI: https://doi.org/10.30749/2594-8261.v3n2p76-93

\section{O SURGIMENTO DOS CENTROS DE DOCUMENTAÇÃO UNIVERSITÁRIOS E SUA RELAÇÃO COM A PNC DE 1975 ${ }^{1}$}

\section{THE ORIGIN OF UNIVERSITY DOCUMENTATION CENTERS AND THE RELATIONSHIP WITH THE PCN OF 1975}

Marcia Teixeira Cavalcanti*

Resumo: Nos anos de 1970 se configura um contexto político social particular, no Brasil, que permite o surgimento dos centros de documentação, especialmente nos espaços universitários. Podemos identificar, neste momento, o surgimento de centros de documentação voltados para a pesquisa histórica, como, por exemplo, o Arquivo Edgar Leuenroth/AEL. Acreditamos que diversos fatores, em conjunto, colaboraram para que esse contexto se configurasse, e que estariam diretamente relacionados não só à academia, mas também aos cenários social, cultural e político do período. Dentre estes fatores destacamos a publicação da Política Nacional de Cultura (PNC) em 1975.

Palavras-Chave: Centros de documentação. Políticas culturais. PNC.

Abstract: In the 1970's , a particular social political context make off in Brazil, which allowed the emergence of documentation centers, especially in university spaces. We can identify at this moment the emergence of documentation centers focused on historical research, such as the Arquivo Edgar Leuenroth/AEL. We believe that several factors together contributed to this context has been configured, which would be directly related not only to the academic world, but also to the social, cultural and political scenarios of the period. Among these factors we highlight the publication of the Política Nacional de Cultura (PNC) in 1975.

Keywords: Documentation Centers. Cultural Policies. PNC.

\footnotetext{
${ }^{1}$ Este artigo se originou da tese de doutorado defendida em 2014, no IBICT/UFRJ e apresentado no VII Seminário Internacional de Políticas Culturais, 2016, Rio de Janeiro.

* Doutora e Mestre em Ciência da Informação, pelo Programa de Pós-Graduação em Ciência da Informação do Instituto Brasileiro de Informação em Ciência e Tecnologia (IBICT), convênio Universidade Federal do Rio de Janeiro (UFRJ). Graduada em Ciências Sociais pela Universidade Federal do Rio de Janeiro em Letras Português-Literatura pela Sociedade de Ensino Superior Estácio de Sá (UNESA). Professora do curso de Administração da Universidade Santa Úrsula (USU). Professora dos cursos de Administração e Pedagogia das Faculdades Integradas Maria Thereza (FAMATH).
} 


\section{INTRODUÇÃO}

Neste trabalho buscamos identificar e analisar os fatores que contribuíram para o surgimento dos centros de documentação nas décadas de 1970/80 dentro de espaços acadêmicos, mais especificamente as universidades, frente o contexto político e social que se instalou no Brasil de 1964 até 1985. Estes espaços cumprem a função de documentar a experiência adquirida pelos indivíduos e grupos em suas vivências individuais, coletivas, políticas, jurídicas etc.

A escolha por este tema partiu de um questionamento existente desde o período do mestrado, em que trabalhamos com o Arquivo de Memória Operária do Rio de Janeiro/AMORJ, um centro de documentação criado na Universidade Federal do Rio de Janeiro/UFRJ em 1986. A partir das leituras realizadas para a dissertação, nos perguntávamos por que estes centros de documentação começam a surgir em diferentes lugares, mas principalmente nos espaços acadêmicos, como também nos intrigava que muitos tenham surgido no período do governo civil militar para preservar documentos reunidos por indivíduos ou grupos que, de alguma forma, viviam situações de conflito e de confronto com o governo instituído.

Como falar de preservação da memória desses atores, que pareciam estar à margem dos espaços comemorativos e do reconhecimento organizado, naquele período? Como acreditamos que neste período recortado o controle sobre a informação era extremamente rígido, as universidades, como espaços de produção de conhecimento e de informação, estariam sob constante vigilância do governo.

Por que estes centros de documentação surgem e se multiplicam nas universidades, neste período tão conturbado de nossa história? Cremos que o próprio governo foi um dos incentivadores na criação destes espaços, e, portanto, partimos para a realização de uma pesquisa documental que pudesse comprovar nossa hipótese. Os indícios encontrados são plurais e complexos, o que nos levou a indagar sobre o papel das universidades e de sua contribuição para o surgimento dos centros de documentação e como essas iniciativas estão vinculadas às políticas culturais implementadas pelo governo civil militar na década de 1970 . 


\section{O SURGIMENTO DOS CENTROS DE DOCUMENTAÇÃO NAS UNIVERSIDADES}

Nos anos de 1970 se configura um contexto político social particular, no Brasil, que permite o surgimento dos centros de documentação, especialmente nos espaços universitários. Podemos identificar, neste momento, o surgimento de centros de documentação voltados para a pesquisa histórica, como, por exemplo, o Arquivo Edgar Leuenroth (AEL), que foi o primeiro arquivo brasileiro de história social a se constituir, no ano de 1974, durante o período do governo civil militar. Acreditamos que diversos fatores, em conjunto, colaboraram para que esse contexto se configurasse, fatores estes que estariam diretamente relacionados não só à academia, mas também aos cenários social, cultural e político do período.

Segundo Moreira (1990), a década de 1960 foi marcada pela pesquisa histórica realizada pelos chamados brasilianistas, os pesquisadores estrangeiros que fizeram um extenso levantamento sobre a História do Brasil em apenas uma década, financiados por agências de fomento e universidades americanas.

Motivadas inicialmente pela surpresa da revolução cubana (1959) que desperta as agências de financiamento e as universidades norteamericanas para a necessidade de conhecer a América Latina e, assim, melhor avaliar a política externa dos EUA - grandes levas de sociólogos, antropólogos, cientistas políticos, e, principalmente, historiadores, passam a vir para cá com o objetivo de explicar a história política e econômica do país, estabelecendo, assim, seu perfil como nação. (MOREIRA, 1990, p. 66).

Esse interesse estadunidense pela América Latina pode ser analisado como uma das formas não só de conhecer esse novo horizonte que se descortina, mas também implementar modos de se impor como modelo de nação, especialmente econômica e política, aos então subdesenvolvidos países latino-americanos. Longe de nos voltarmos para esta questão, o que nos interessa é perceber que o governo que se institui a partir de 1964, de certa forma, também se utiliza dos meios acadêmicos para obter informação sobre sua população, sendo o viés da memória e de sua preservação uma forma eficaz de realização deste intento. Podemos ilustrar esta ideia a partir dos incentivos que ele passa a dar às universidades para a criação 
de centros de documentação que dessem suporte à pesquisa acadêmica em diferentes áreas, expressos em sua Política Nacional de Cultura.

A temática dos brasilianistas nos é importante porque a partir de suas pesquisas passamos a tomar conhecimento dos diversos problemas que surgem no Brasil relacionados às pesquisas acadêmicas, dentre eles o que nos interessa é justamente a situação do acesso dos pesquisadores aos documentos necessários às suas pesquisas, e, consequentemente, à informação. Segundo Moreira (1990), além da própria deficiência nos cursos de formação universitários, voltados essencialmente para a formação de professores e não de pesquisadores, e a falta de uma estrutura financeira eficaz no que tange ao desempenho profissional, é preciso acrescentar a dificuldade de acesso aos documentos pelos pesquisadores brasileiros, principalmente pela inexistência de uma lei geral que regulamentasse o funcionamento dos arquivos.

Mesmo para esses pesquisadores estrangeiros, a consulta a determinados documentos foi tão dificultosa quanto para os brasileiros, justamente pela quase inexistência de acervos documentais disponíveis organizados em espaços próprios e que permitissem o acesso à informação especializada. Para Moreira (1990), outra dificuldade relacionada à produção acadêmica no período inclui a própria condição de marginalidade a que foram confinados muitos pesquisadores após a implantação do governo civil militar, com a demissão de um número significativo de professores das universidades públicas.

Segundo Moreira (1990), ao analisar a atuação do CNPq pode-se perceber que somente em 1966 as Ciências Sociais e Humanas foram incorporadas aos setores do conhecimento reconhecidos por este órgão, e somente em 1976 deixou de ser a área que menos recurso recebeu. Em 1975 o Programa de Apoio à Cultura (Procultura) direcionou recursos para a implementação de projetos na área de Ciências Sociais, visando a ampliação e o aperfeiçoamento dos programas de pósgraduação e a realização de pesquisas.

Ainda a partir de 1975, esse movimento de apoio às ciências sociais foi reforçado com a nova política nacional de cultura definida pelo Ministério da Educação e Cultura, que, ao estabelecer a participação das universidades nas atividades de levantamento de acervos arquivísticos com valor histórico, estimulou, por seu lado, o 
surgimento de centros de documentação vinculados aos estabelecimentos federais de ensino. (MOREIRA, 1990, p. 73).

Ao falar dos centros de documentação não podemos deixar de abordar as questões relacionadas à memória nacional. Até a década de 1970 podemos afirmar, com certa margem de segurança, que a preocupação com a chamada memória documental, no Brasil, era restrita a algumas poucas pessoas e instituições. Com relação à pesquisa no campo da História, a memória (mal) preservada se relacionava a lugares como o Instituto Histórico e Geográfico Brasileiro (IHGB) e arquivos públicos, sempre com ênfase na documentação relativa à Colônia e ao Império. Novos interesses de pesquisa neste campo, que se volta para o período republicano, não encontravam retorno nas principais instituições de arquivo existentes, pois as fontes históricas tratadas e disponibilizadas para pesquisa eram escassas, além de evidenciarem a própria dificuldade em que estas instituições se encontravam com relação ao atendimento da demanda que surge por parte dos pesquisadores.

Podemos supor que os pesquisadores ampliaram 0 interesse pela compreensão da sociedade brasileira e não se restringiram mais, ou apenas, a analisar ou buscar uma identidade nacional. Esta busca perpassava outros caminhos e temáticas, como as questões femininas, dos trabalhadores, do negro etc. Segundo Costa,

O Arquivo Nacional, criado em 1838, e os arquivos públicos estaduais e municipais, organizados somente após o advento da República, apresentavam problemas de natureza diversa, que dificultavam o desenvolvimento de suas atribuições de recolher, preservar e dar acesso aos documentos oriundos dos órgãos da administração pública $A$ inexistência de um modelo sistêmico de arquivos, bem como a carência de recursos humanos e materiais contribuiu, entre outros fatores, para que os documentos gerados pelo poder público fossem descartados de forma arbitrária e recolhidos assistematicamente. Tal realidade dificultou e por vezes impediu o tratamento e acesso a um volume considerável de documentos, sobretudo os de períodos mais recentes. (COSTA et al, 1986 apud MOREIRA, 1990, p. 69).

Portanto, as novas demandas da pesquisa histórica corroboraram a necessidade que passou a surgir de se preservar estes documentos, incluindo aí até 
mesmo os documentos privados (documentos particulares de indivíduos, famílias, grupos de interesse ou empresa), e também expos a falta de legislação e de uma política voltada para arquivos e para a preservação da memória nacional.

Moreira (1990) identifica o surgimento dos centros de documentação ao longo da década de 1970 como uma resposta a essa necessidade, e reflexo até mesmo desta reconfiguração da ordem, pois eles tinham como objetivo principal, segundo a autora, a preservação dos documentos contemporâneos, principalmente os privados.

Mas não podemos esquecer que em 1975 é publicada a Política Nacional de Cultura, que objetivava preservar o patrimônio artístico e histórico nacional, tendo os museus, bibliotecas e as diversas categorias de arquivos um papel importante para a preservação da cultura nacional. Como o governo propôs fazer isso? Ele passa a incentivar a preservação dos arquivos nacionais, estaduais ou locais, incluindo até mesmo os arquivos particulares, podendo estes arquivos ser incorporados aos arquivos oficiais. E vai além, destacando o papel das universidades neste processo e incentivando estas a criarem arquivos e centros de documentação.

Segundo Knauss (2009), os centros de documentação universitários se constituem em uma espécie ímpar dentro do universo dos arquivos na atualidade. E sua unicidade decorre do fato de que surgem como núcleos de apoio à pesquisa, mas também pelo seu perfil diversificado, pois além de custodiarem diferentes tipos de acervos (museológicos, arquivísticos e bibliográficos), vão além e produzem instrumentos de pesquisa (bases de dados, guias etc.).

Os centros de documentação criados nos ambientes universitários, frequentemente, ocupam um espaço deixado em aberto pelas instituições públicas. Além de preservarem os documentos privados, eles também acabam por resgatar documentos de valor histórico que estejam com sua integridade ameaçada, como documentos jurídicos, cartorários etc.

Camargo (2003), analisando um texto de Sérgio Miceli de 1984, mostra como este chamou a atenção para um processo que ele nomeou de "estatização da cultura" no Brasil dos anos 1970, quando analisa as diferentes iniciativas do governo para a proteção do patrimônio cultural e do aparato institucional estatal que estendia seu alcance às diversas dimensões do ato cultural. 
Uma de suas principais constatações era a de que, ao contrário do que se poderia supor, não foi apenas o Ministério da Educação e Cultura (MEC) que, por força de suas atribuições, esteve envolvido nesse processo. A Secretaria de Planejamento da Presidência da República, o Ministério do Interior, o Banco do Brasil, a Caixa Econômica Federal, entre outros, participaram ativamente de programas federais voltados para a criação cultural e, particularmente, para o desenvolvimento da vertente patrimonial de uma política nacional de cultura. Esse movimento foi acompanhado pelos estados e municípios brasileiros, que historicamente tendem a reproduzir o modelo federal em suas respectivas esferas de poder. $\mathrm{O}$ mundo empresarial, não somente pelo desenvolvimento da indústria cultural e pela prática do mecenato - que passou a ser estimulada pelo poder público -, também integrou esse conjunto de iniciativas, voltando-se para a sua própria memória e para a produção de uma história empresarial no Brasil. (CAMARGO, 2003, p. 24-25).

$\mathrm{Na}$ área das humanidades verifica-se que, desde a década de 1970, várias universidades partiram para a resolução de um dos principais problemas com os quais se deparava o pesquisador, que era a falta de acesso aos documentos necessários à realização da pesquisa. Isso ocorria tanto pela ausência de instituições voltadas para a preservação destes documentos como pelo descaso do poder público e instituições privadas que não destinavam, até então, recursos financeiros e humanos para a sua organização e preservação. A Política Nacional de Cultura (PNC) vem como uma resposta a esse impasse, publicada em 1975, além de recomendar a criação destes centros delegava as universidades a função de preservar e organizar estes acervos (CAMARGO, 2003).

Os centros de documentação criados nas universidades, em especial nas áreas de humanidades, letras e artes, inicialmente não conseguiram reconhecimento e apoio como órgãos geradores de base informativa, acreditamos que o motivo tenha sido o fato de que naquele momento o modelo de desenvolvimento econômico do país priorizava o conhecimento gerado pela área tecnológica. Para que pudessem ser criados precisaram assumir também a função de preservação da memória, especialmente a memória regional (CAMARGO, 1999).

O início da década de 1970 vê surgir no Brasil os primeiros centros de documentação voltados para a pesquisa histórica: o Centro de documentação do Instituto de Filosofia e Ciências Humanas da Universidade de Campinas-, Unicamp (1971); o Centro de Memória 
Social Brasileira, do Conjunto Universitário Cândido Mendes (1972), e o Centro de Pesquisa e Documentação de História Contemporânea do Brasil - CPDOC, da Fundação Getúlio Vargas (1973). (MOREIRA, 1990, p. 66).

Os motivos que deram origem a estes centros, combinados entre si, não são suficientes para explicar seu surgimento e sua proliferação, acreditamos que políticas públicas no campo da cultura, além da reforma na educação, também tenham ajudado para que estes espaços de memória se multiplicassem nas décadas de 1970/80.

\section{O ESTADO E A CULTURA}

A atuação do Estado no setor cultural durante o período do governo civil militar foi muito mais profícua do que podemos imaginar, existindo uma preocupação e incentivos por parte dos diferentes governos instituídos ao longo do período (19641985), com a cultura tornando-se até mesmo um setor estratégico. Diferentes instituições dedicadas à cultura nacional são criadas, além de programas, documentos e campanhas.

A construção da política cultural no governo civil militar seguiu os moldes da Doutrina da Escola Superior de Guerra (ESG), por ter sido um projeto nacional para o desenvolvimento do Brasil nos moldes defendidos pelas Forças Armadas (SILVA, 2001). A decisão do governo de estimular o desenvolvimento cultural fundamenta-se num conjunto de legislações, como a Constituição Federal e Decretos-Lei, sendo o de número 200, de 25.2.1967, em seu artigo 39, o que inclui a cultura como área de competência do Ministério da Educação e Cultura: "SETOR SOCIAL. MINISTÉRIO DA EDUCAÇÃO E CULTURA. I - Educação; ensino (exceto o militar); magistério. II Cultura - letras e artes. III - Patrimônio histórico, arqueológico, científico, cultural e artístico. IV - Desportos." (BRASIL, 1967, art. 39).

Essa atuação por parte do Estado na área da cultura resultou na criação, em 1975, de uma Política Nacional de Cultura (PNC), um programa político criado por Ney Braga, que estava à frente do antigo Ministério de Educação e Cultura durante o governo do General Geisel, pois ainda não existia um ministério apenas da cultura. 
Este documento pode ser visto como uma forma encontrada pelo governo de reconhecer de maneira oficial a necessidade da inclusão da cultura nos projetos de desenvolvimento previstos para o país, pois, de acordo com o discurso governamental do período, a construção do futuro de um país não se fundamenta apenas em alicerces materiais.

Para isso, o Estado deve atuar no sentido de incentivar a produção de cultura e generalizar ao máximo seu consumo, entendendo cultura a partir de duas vertentes: como elemento de identidade nacional e como elemento criador de civilização.

No ano de 1966 foi formada uma comissão com a função de apresentar sugestões para a reformulação cultural do país, que propõe a criação de um conselho como o Conselho Federal de Educação. Neste mesmo ano, em 12 de novembro, foi criado, sob a presidência de Castello Branco, o Conselho Federal de Cultura (CFC), pelo Decreto-Lei oㅜ 74/1966, tendo o início de suas atividades em 1967 e seu funcionamento até 1990, quando da sua extinção. O objetivo da criação deste órgão era decidir sobre assuntos pertinentes às artes, às letras, às ciências e ao patrimônio histórico e artístico nacional, ou seja, institucionalizar a ação do Estado no setor cultural (MAIA, 2012a, p. 35). E suas atribuições principais eram a elaboração do Plano Nacional de Cultura e a formulação da política cultural nacional.

Sua constituição se deu em quatro câmaras - Artes, Ciências Humanas, Letras e Patrimônio Histórico e Artístico - para deliberação dos assuntos de sua competência, e para decidir sobre matéria de caráter geral ocorriam reuniões em sessão. Além da elaboração do Plano Nacional de Cultura outras dezenove atribuições foram estabelecidas ao CFC, dentre elas:

1) formular a política cultural nacional; 2) articular-se com os órgãos federais, estaduais e municipais, bem como as Universidades e instituições culturais, de modo a assegurar a coordenação e a execução dos programas culturais; 3) promover a defesa e conservação do patrimônio histórico e artístico nacional; 4) conceder auxílios e subvenções às instituições culturais oficiais e particulares de utilidade pública, tendo em vista a conservação de seu patrimônio artístico e a execução de projetos específicos para a difusão da cultura científica, literária e artística; 5) promover campanhas nacionais que visem ao desenvolvimento cultural e artístico; 6) manter atualizado o registro das instituições culturais e oficiais e 
particulares e dos professores e artistas que militam no campo das ciências, das letras e das artes; 7) reconhecer, para efeito de assistência e amparo através do Plano Nacional de Cultura, as instituições culturais do País, cujo reconhecimento se dará mediante solicitação da instituição interessada; 8) estimular a criação de Conselhos Estaduais de Cultura e propor convênios com esses órgãos, visando ao levantamento das necessidades regionais e locais, nos diferentes ramos profissionais, e ao desenvolvimento e integração da cultura no País; 9) elaborar o Plano Nacional da Cultura, com os recursos oriundos do Fundo Nacional da Educação, ou de outras fontes, orçamentárias ou não, colocadas ao seu alcance. (BRASIL, 1966, art. 2).

Ao lado da figura do Estado repressor vemos uma tentativa de recuperação de sua imagem no campo da cultura com a criação do CFC. No discurso de instalação do CFC o Presidente Castelo Branco declara que:

Não estaria concluída a obra da Revolução no campo intelectual se, após trabalhos tão profícuos em benefício da educação, deixasse de se voltar para os problemas da cultura nacional. Representada pelo que através dos tempos se vai sedimentando nas bibliotecas, nos monumentos, nos museus, no teatro, no cinema e nas várias instituições culturais, é ela, naturalmente, nesse binômio educação e cultura, a parte mais tranquila e menos reivindicante. Poderia dizer que é a parte dos cabelos brancos, e, talvez, por isso, já segura do que fez e do que fará pelo Brasil. Cumpre, porém, dar-lhe principalmente, condições de preservação, e, portanto, de sobrevivência e evolução. (CONSELHO FEDERAL DE CULTURA, 1975, p. 21-22).

Pelo conteúdo do decreto-lei de sua criação é possível percebermos que o objetivo do CFC, além da formulação de uma política cultural nacional, também se voltava para a preservação do patrimônio histórico e artístico. O que permitia a construção de uma identidade nacional e ao mesmo tempo a defesa de um determinado projeto político para o país, definido pelos militares e civis que o apoiaram, sendo instrumentos importantes incluídos neste projeto a cultura, a memória e a informação.

Por força do decreto-lei de sua criação, o novo órgão do Ministério da Educação e Cultura tinha apenas o caráter normativo, consultivo e fiscalizador, tal como definido no seu Regimento. Na prática, o Conselho tornou-se encarregado pela distribuição das verbas; financiamento de instituições públicas e privadas do setor cultural; assessoramento ao ministro da Educação e Cultura; definição das 
áreas de atuação do Estado; realização de convênios com instituições culturais; elaboração de regulamentos e resoluções; organização de campanhas nacionais de cultura; e defesa do patrimônio cultural. (MAIA, 2012b, p. 3).

Foram feitos convênios com diferentes instituições voltadas para a defesa da cultura e do patrimônio cultural nacional objetivando a compra de materiais, equipamentos, restauro de fachadas. Estes convênios também buscavam garantir a essas instituições todas as condições indispensáveis para a implementação dos programas instituídos. Como uma destas instituições, as universidades aparecem com a função de coordenar e executar programas culturais. Apesar de aparentemente estarem em campos opostos na arena política e social durante o período do governo civil militar, estes dois agentes, universidade e governo, muitas vezes acabam por estabelecer alianças, traçando projetos comuns, que atendessem aos interesses de ambas as partes.

Para promover a defesa e conservação do patrimônio o CFC também contava com a realização de convênios, existindo dentro do conselho a câmara para o patrimônio histórico e artístico nacional, sendo de competência desta câmara a deliberação de verbas oriundas do Ministério da Educação e Cultura para a manutenção de prédios e acervos documentais e bibliográficos dos Institutos Históricos e Geográficos. A concessão de "[...] auxílios e subvenções às instituições culturais oficiais e particulares de utilidade pública, tendo em vista a conservação de seu patrimônio artístico e a execução de projetos específicos para a difusão da cultura científica, literária e artística." (BRASIL, 1966, art. 2) somente poderia ocorrer se a instituição solicitante estivesse registrada junto ao conselho. Além das obras arquitetônicas o CFC considerava como patrimônio nacional também os museus e as bibliotecas.

No ano de 1975 foi criada a Política Nacional de Cultura (PNC), um documento elaborado pelo Ministério da Educação e Cultura (MEC) que contou com a contribuição do Conselho Federal de Cultura.

De acordo com as evidências de que dispomos, a elaboração e redação do documento enfim aprovado resultou de um trabalho coletivamente diluído entre os principais dirigentes culturais do MEC na época da gestão Ney Braga, mormente os ocupantes de cargos 
decisórios, como o prof. Manuel Diegues Jr., diretor do DAC; Roberto Parreira, gestor do DAC, prof. Carlos Alberto Direito, chefe de gabinete; ao lado de mentores da área cultural oficial, entre os quais, intelectuais eminentes do CFC, como por exemplo Josué Montello, Artur César Ferreira Reis, Clarival do Prado Valladares, Afonso Arinos de Melo Franco, Gilberto Freyre, entre outros. (MICELI, 1984, p. 57 , nota 11).

O texto introdutório, assinado pelo Ministro Ney Braga, esclarece que a divulgação da PNC completa a elaboração de políticas específicas para as três áreas de atuação do MEC, ainda estando em fase de execução a Política Nacional Integrada da Educação e a Política Nacional de Educação Física e Desportos. Neste documento estão contidos:

a) a concepção básica do que se entende por uma política de cultura;

b) definir e situar, no tempo e espaço, a cultura brasileira;

c) explicitar os fundamentos legais da ação do governo no campo cultural;

d) traçar diretrizes que nortearão o trabalho do MEC;

e) detalhar objetivos e componentes da Política Nacional de Cultura;

f) exprimir ideias e programas;

g) revelar as formas de ação.

O objetivo central da ação do MEC consistia em "apoiar e incentivar as iniciativas culturais de indivíduos e grupos e zelar pelo patrimônio cultural da Nação, sem intervenção do Estado, para dirigir a cultura." (BRASIL, 1975, p. 5). Podemos perceber neste trecho uma certa preocupação do ministro Ney Braga em se defender de qualquer tipo de acusação de tentativa de controle ou até mesmo de manipulação da produção cultural. Não podemos esquecer que na década de 1970 o Presidente Geisel inicia um período de abertura política em que a cultura assume um importante papel como espaço de diálogo entre os intelectuais e o regime instituído, basta vermos os integrantes dos quadros do CFC e até mesmo os que contribuíram na formulação da PNC.

Segundo Cohn (1984), a publicação da PNC em 1975 seria o ponto culminante de um processo que "percorreu toda a primeira metade da década, de busca de um equacionamento da cultura adequado ao regime político que se procurava consolidar" (COHN, 1984, p.87). Para ele, a busca de uma política 
nacional de cultura no período tem um objetivo bem definido: a codificação do controle sobre o processo cultural, já que no terreno da cultura o regime político se encontrava em posição de desvantagem, com uma relativa hegemonia cultural da esquerda no país. O lançamento da PNC vem consolidar a importância da necessidade de incluir a cultura nos planos de desenvolvimento nacional.

A PNC esclarece que essa política (cultural) significa a presença do Estado como um elemento de estímulo e apoio às diferentes manifestações culturais e apresenta um conjunto de oito diretrizes que condicionam e orientam a ação do governo como instrumento de estímulo e formação de manifestações culturais:

1. o respeito as diferenciações regionais da cultura brasileira, oriundas da formação histórica e social do País, procurando relacioná-las em seu próprio contexto; 2 . a proteção, a salvaguarda e a valorização do patrimônio histórico e artístico e ainda dos elementos tradicionais geralmente traduzidos em manifestações folclóricas e de artes populares, características de nossa personalidade cultural, expressando o próprio sentimento da nacionalidade; 3 . o respeito à liberdade de criação, em todos os campos da cultura, fator precípuo para que esta possa desenvolverse dentro das aptidões de cada um e através da vocação criativa do espírito humano; 4. o estímulo à criação nos diversos campos das letras, das artes e artesanato, das ciências e da tecnologia, bem como a outras expressões do espírito do homem brasileiro, visando à difusão desses valores através dos meios de comunicação de massa; 5. o apoio à formação de profissionais que contribua para desenvolver uma consciência nacional capaz de zelar e dar continuidade ao que é culturalmente nosso; 6. o incentivo aos instrumentos materiais, atuantes ou em potencial, para imprimir maior desenvolvimento à criação e à difusão das diferentes manifestações da cultura, tendo-se sempre em vista a salvaguarda dos nossos valores culturais, ameaçados pela imposição maciça, através dos novos meios de comunicação, dos valores estrangeiros; 7. a maior aproximação da cultura brasileira com a de outros povos, como elemento capaz de estimular a atividade criadora e, ao mesmo tempo, promover maior contato entre diferentes realidades nacionais, possibilitando assim o acolhimento do que representa criação de outros grupos humanos dentro da própria vocação brasileira, aberta aos mais amplos contatos e à compreensão do sentido pluralista da cultura contemporânea, em suas diversas expressões; 8.0 desenvolvimento nacional não é puramente econômico, mas também sociocultural, ao abranger a plena participação de cada indivíduo como gerador e assimilador de cultura, contribuindo de maneira efetiva para elevar o nível de vida. (BRASIL, 1975, p. 24-25). 
Ao final atribui a responsabilidade de coordenação destas ações por parte do Estado ao Ministério da Educação e Cultura, sendo que isto se dará através de dois órgãos especializados, o Conselho Federal de Cultura, normativo e incentivador, e o Departamento de Assuntos Culturais (DAC), ficando as unidades a este subordinadas ou vinculadas como órgãos executivos.

Dentre os objetivos da Política Nacional de Cultura podemos apontar o de preservar os bens de valor cultural, tendo como meta resguardar o acervo constituído e manter viva a memória nacional, assegurando a perenidade da cultura brasileira. $O$ desaparecimento do acervo cultural acumulado e 0 desinteresse pela contínua acumulação da cultura, segundo o documento, representa risco para a preservação da personalidade brasileira e, portanto, para a segurança nacional. Mas preservar não significa uma atitude de conservação e sim manter a vivência do povo em consonância com os valores vigentes. Segundo Miceli (1984), a noção de patrimônio presente na PNC envolve tanto o acervo associado à história dos grupos dirigentes como às tradições e costumes das classes populares (folclore ou populário).

A parte do documento que cita a dificuldade encontrada na formação de profissionais com conhecimentos básicos específicos como um dos obstáculos existentes para dinamizar e desenvolver as atividades no âmbito da cultura pode ser relacionada com os incentivos promovidos pelo governo, via MEC e CNPq, na capacitação de profissionais tanto na formação básica quanto na superior, incluindo aí a pós-graduação.

Ainda não existia no Brasil, antes do período do governo civil militar, um esforço articulado e com metas claras que ligasse 0 desenvolvimento socioeconômico ao conhecimento científico e tecnológico, e muito menos que relacionasse estes dois com a cultura. Mas a PNC deixa muito claro, no item objetivo, que na estratégia do desenvolvimento a intensificação destes objetivos propostos representa uma das ações fundamentais. Para que o Brasil ocupe uma posição de vanguarda não são suficientes o desenvolvimento econômico, a ocupação do território, a industrialização, dentre outros. É necessário que ele desenvolva uma cultura vigorosa que lhe dê uma personalidade nacional forte e influente. 
Nesse rumo de concepções e na conformidade de nossa vocação democrática, a Política Nacional de Cultura entrelaça-se, como área de recobrimento, com as políticas de segurança e de desenvolvimento; significa, substancialmente, a presença do Estado como elemento de apoio e estímulo à integração do desenvolvimento cultural dentro do processo global de desenvolvimento brasileiro. (BRASIL, 1975, p. 30).

O documento apresenta nove componentes básicos entendidos como os elementos para a ação do Ministério da Educação e Cultura no setor. Dentre estes componentes, nos interessa explicitamente o de número 3 :

Revalidação do patrimônio histórico e científico brasileiro - Abrange a preservação do patrimônio artístico e histórico propriamente dito, e mais o paisagístico, o arqueológico e o etnográfico. O objetivo central é preservar os símbolos culturais de nossa história. Nessa área, desempenham também papel básico os museus, as bibliotecas e as diversas categorias de arquivos. (BRASIL, 1975, p. 33).

Aparece pela primeira vez no documento a menção à importância dos arquivos, além dos museus e bibliotecas, como órgãos necessários para a execução destes objetivos de preservação da cultura nacional.

Os meios adotados pelo governo e considerados por ele como adequados para a execução destas medidas englobam ideias e programas que visem atender a uma lista de quinze itens. Dentre estes itens nos chama atenção o que pretende incentivar a preservação dos arquivos nacionais, estaduais ou locais, de modo particular os de caráter eclesiástico, além de incentivar a conservação de arquivos particulares ou a incorporação dos documentos conservados pelas famílias aos arquivos oficiais.

f) incentivar a preservação dos arquivos nacionais, estaduais ou locais, de modo particular os de caráter eclesiástico, considerada a importância da paróquia na vida das diferentes regiões do País, e estimular ao mesmo tempo a conservação de arquivos particulares ou a incorporação dos documentos conservados em famílias aos arquivos oficiais. (BRASIL, 1975, p. 36-37). 
Podemos considerar, no mínimo, curioso este item, pois não existia no país, naquele período, nenhuma política que se voltasse especificamente para arquivos, ou seja, uma política nacional de arquivo, e como acontecia com a maioria dos assuntos sem uma pasta específica, se coubessem eles eram discutidos na pasta da cultura. Segundo Jardim (2008), somente em janeiro de 1991 o Estado brasileiro passa a contar com um Conselho Nacional de Arquivos - CONARQ, que seria incumbido de definir uma política nacional de arquivos e atuar como órgão central de um Sistema Nacional de Arquivos - SINAR.

O último item do documento, intitulado formas de ação, descreve as ações que deveriam ser tomadas para a execução das medidas apresentadas e indispensáveis à realização de seus programas. Essas diversas formas de ação levavam em conta a regionalização cultural do Brasil e o sistema de cooperação que deveria ser estabelecido para se implementar os projetos decorrentes da Política Nacional de Cultura. Também apresentava os órgãos que deveriam fazer parte deste sistema de cooperação, composto pelo CFC, DAC, Unidades federadas, Ministérios, Secretarias e, dentro do nosso interesse neste trabalho, as universidades, consideradas como focos capazes de contribuir para o surgimento do espírito científico e criativo ao associar análise e pesquisa, cabendo a elas:

b) promover estudos e pesquisas, em nível de planejamento próprio ou em convênio com outras instituições culturais, para levantamento de acervos arqueológicos, históricos, etnográficos, artísticos ou folclóricos, centralizando os dados em organizações de livre acesso aos estudiosos. Constituir centros de documentação iconográfica e de reprografia dos acervos e manifestações culturais de suas áreas; c) incentivar o levantamento da documentação histórica, científica e artística de referência imediata ao Brasil, de diversa data ou atual, retida em fontes estrangeiras, para a obtenção de reproduções ou reprografias destinadas às instituições brasileiras atinentes a cada especialização; d) construir centros de documentação iconográfica e de reprografia dos acervos e manifestações culturais de suas áreas. (BRASIL, 1975, p. 41). 


\section{CONSIDERAÇÕES FINAIS}

Ao longo do texto discorremos sobre como os militares, durante sua permanência no governo, interferiram no cenário cultural via a elaboração de uma Política Nacional de Cultura (PNC), que buscava preservar uma memória e cultura nacionais. Entendemos, portanto, que o efeito desta política ocorre em função da preocupação com a preservação de uma cultura e uma memória nacionais presentes na sociedade da época.

Ao fixar formas de ação, a PNC criou um sistema de cooperação que deveria ser realizado com a participação de diferentes órgãos, inclusive as universidades. Para atender às demandas apresentadas, era preciso que estes órgãos se estruturassem, e, no caso das universidades, a criação dos centros de documentação é um sinal dessa estruturação. Se, segundo Camargo (2003), é possível percebermos um movimento voltado para a criação de centros de documentação e pesquisa, memória e referência nas universidades, especialmente a partir de 1975, acreditamos que a PNC vem embasar esse movimento.

\section{REFERÊNCIAS}

BRASIL. Decreto-lei no 74, de 21 de novembro de 1966. Cria o Conselho Federal de Cultura e dá outras providências. Brasília, DF: Presidência da República,1966. Disponível em: http://www2.camara.leg.br/legin/fed/declei/1960-1969/decreto-lei-7421-novembro-1966-375931-republicacao-35524-pe.html. Acesso em: 10 fev. 2018.

Decreto-lei no 200, de 25 de fevereiro de 1967. Dispõe sôbre a organização da Administração Federal, estabelece diretrizes para a Reforma Administrativa e dá outras providências. Brasília, DF: Presidência da República,1967. Disponível em: http://www.planalto.gov.br/ccivil_03/decretolei/del0200.htm. Acesso em: 10 fev. 2018.

. Ministério da Educação e Cultura. Política Nacional de Cultura.

Brasília: Departamento de Documentação e Divulgação, 1975.

CAMARGO, Célia Reis. Centros de documentação e pesquisa histórica: uma trajetória de três décadas. In: CENTRO DE PESQUISA E DOCUMENTAÇÃO DE HISTÓRIA CONTEMPORÂNEA DO BRASIL. CPDOC 30 anos. Rio de Janeiro: Ed. Fundação Getulio Vargas; CPDOC, 2003. 
. Os Centros de Documentação das universidades: tendências e perspectivas. In: SILVA, Zélia Lopes da (org.). Arquivos, patrimônio e memória. Trajetórias e perspectivas. São Paulo: Ed. UNESP; FAPESP, 1999. cap. 4, p. 4964.

COHN, Gabriel. A concepção oficial da política cultural nos anos 70. In: MICELI, Sérgio (org.). Estado e Cultura no Brasil. São Paulo: Difel, 1984.

CONSELHO FEDERAL DE CULTURA. Aspectos da política cultural brasileira. Rio de Janeiro: MEC, 1975.

JARDIM, José Maria. Políticas públicas de informação: a (não) construção da política nacional de arquivos públicos e privados (1994-2006). In: ENCONTRO NACIONAL DE PESQUISA EM CIÊNCIA DA INFORMAÇÃO, 9., 2008, São Paulo. Anais [...]. São Paulo: USP, 2008.

KNAUSS, Paulo. Usos do passado: arquivos e universidades. Cadernos de Pesquisa do CDHIS, ano 22, n. 40, p. 09-16, jan./jun. 2009.

MAIA, Tatyana de Amaral. Os cardeais da cultura nacional: o Conselho Federal de Cultura na ditadura civil-militar (1967-1975). São Paulo: Itaú Cultural; Iluminuras, 2012a. (Rumos Pesquisa).

. Políticas culturais e patrimônio histórico: as ações do Conselho Federal de Cultura (1967-1975). Revista Memória em Rede, Pelotas, v. 2, n. 7, p. 1-17, jul./dez. $2012 b$.

MICELI, Sérgio (org.). Estado e Cultura no Brasil. São Paulo: Difel, 1984.

MOREIRA, Regina da L. Brasilianistas, historiografia e centros de documentação. Estudos Históricos. Rio de Janeiro, v. 3, n. 5, p. 66-74, 1990.

SILVA, Vanderli Maria da. A construção da política cultural no regime militar: concepções, diretrizes e programas (1974-1978). 2001. Dissertação (Mestrado em Sociologia) - Faculdade de Filosofia, Letras e Ciências Humanas, Universidade de São Paulo, São Paulo, 2001.

Recebido em 18/09/2019.

Aceito em 02/10/2019. 